\title{
Extra high superoxide dismutase in host tissue is associated with improving bleaching resistance in "thermal adapted" and Durusdinium trenchii-associating coral"
}

\author{
Jih-Terng Wang ${ }^{\text {Corresp., } 1}$, Yi-Ting Wang ${ }^{1}$, Chaolun A Chen ${ }^{2}$, Pei-Jei Meng ${ }^{3,4}$, Kwee Siong Tew ${ }^{4,5}$, Pei-Wen Chiang ${ }^{2}$, \\ Sen-Lin Tang ${ }^{\text {Corresp. } 2}$ \\ ${ }^{1}$ Department of Oceanography, National Sun Yat-Sen University, Kaohsiung, Taiwan \\ 2 Biodiversity Research Center, Academia Sinica, Taipei, Taiwan \\ ${ }^{3}$ General Education Center, National Dong Hwa University, Hualien, Taiwan \\ 4 National Museum of Marine Biology and Aquarium, Pingtung, Taiwan \\ 5 Institute of Marine Biodiversity and Evolution, National Dong Hwa University, Pingtung, Taiwan \\ Corresponding Authors: Jih-Terng Wang, Sen-Lin Tang \\ Email address: jtw100@mail.nsysu.edu.tw, sltang@gate.sinica.edu.tw
}

Global warming threatens reef-building corals with large-scale bleaching events; therefore, it is important to discover potential adaptive capabilities for increasing their temperature resistance before it is too late. This study presents two coral species (Platygyra verweyi and Isopora palifera) surviving on a reef having regular hot water influxes via a nearby nuclear power plant that exhibited completely different bleaching susceptibilities to thermal stress, even though both species shared several so-called "winner" characteristics (e.g., containing Durusdinium trenchii, thick tissue, etc.). During acute heating treatment, algal density did not decline in $P$. verweyi corals within three days of being directly transferred from 25 to $31{ }^{\circ} \mathrm{C}$; however, the same treatment caused I. palifera to lose > $70 \%$ of its algal symbionts within $24 \mathrm{~h}$. The most distinctive feature between the two coral species was an overwhelmingly higher constitutive superoxide dismutase (ca. 10-fold) and catalase (ca. 3-fold) in P. verweyi over I. palifera. Moreover, P. verweyi also contained significantly higher saturated and lower mono-unsaturated fatty acids, especially a longchain saturated fatty acid (C22:0), than I. palifera, and was consistently associated with the symbiotic bacteria Endozoicomonas, which was not found in I. palifera. However, antibiotic treatment and inoculation tests did not support Endozoicomonas having a direct contribution to thermal resistance. This study highlights that, besides its association with a thermally tolerable algal symbiont, a high level of constitutive antioxidant enzymes in the coral host is crucial for coral survivorship in the more fluctuating and higher temperature environments. 
1 Extra high superoxide dismutase in host tissue is associated with improving bleaching resistance

3

4 5

6

$7 \quad{ }^{1}$ Department of Oceanography, National Sun Yat-sen University, Kaohsiung, Taiwan

$8 \quad{ }^{2}$ Biodiversity Research Center, Academia Sinica, Taipei, Taiwan

$9 \quad{ }^{3}$ National Museum of Marine Biology and Aquarium, Pingtung, Taiwan

$10{ }^{4}$ General Education Center, National Dong Hwa University, Hualien, Taiwan

$11{ }^{5}$ Institute of Marine Biodiversity and Evolution, National Dong Hwa University, Pingtung, 12 Taiwan

13

14

15

16

17

18

19

20

21

22

23

24

25

26

27

Jih-Terng Wang ${ }^{1 *}$, Yi-Ting Wang ${ }^{1}$, Chaolun Allen Chen ${ }^{2}$, Pei-Jei Meng ${ }^{3,4}$, Kwee Siong Tew ${ }^{3,5}$, Pei-Wen Chiang ${ }^{2}$, Sen-Lin Tang ${ }^{2 *}$

${ }^{*}$ Corresponding authors:

Jih-Terng Wang,

Department of Oceanography, National Sun Yat-sen University, Kaohsiung, Taiwan

E-mail: jtw100@mail.nsysu.edu.tw

Sen-Lin Tang

Biodiversity Research Center, Academia Sinica, Taipei, Taiwan

E-mail: sltang@gate.sinica.edu.tw 


\section{Abstract}

29 Global warming threatens reef-building corals with large-scale bleaching events; therefore, it is 30 important to discover potential adaptive capabilities for increasing their temperature resistance 31 before it is too late. This study presents two coral species (Platygyra verweyi and Isopora 32 palifera) surviving on a reef having regular hot water influxes via a nearby nuclear power plant 33 that exhibited completely different bleaching susceptibilities to thermal stress, even though both 34 species shared several so-called "winner" characteristics (e.g., containing Durusdinium trenchii, 35 thick tissue, etc.). During acute heating treatment, algal density did not decline in $P$. verweyi 36 corals within three days of being directly transferred from 25 to $31^{\circ} \mathrm{C}$; however, the same 37 treatment caused I. palifera to lose $>70 \%$ of its algal symbionts within $24 \mathrm{~h}$. The most 38 distinctive feature between the two coral species was an overwhelmingly higher constitutive 39 superoxide dismutase (ca. 10-fold) and catalase (ca. 3-fold) in P. verweyi over I. palifera. 40 Moreover, $P$. verweyi also contained significantly higher saturated and lower mono-unsaturated 41 fatty acids, especially a long-chain saturated fatty acid (C22:0), than I. palifera, and was 42 consistently associated with the symbiotic bacteria Endozoicomonas, which was not found in $I$. 43 palifera. However, antibiotic treatment and inoculation tests did not support Endozoicomonas 44 having a direct contribution to thermal resistance. This study highlights that, besides its 45 association with a thermally tolerable algal symbiont, a high level of constitutive antioxidant 46 enzymes in the coral host is crucial for coral survivorship in the more fluctuating and higher 47 temperature environments. 
50

51

52

53

54

55

56

57

58

59

60

61

62

63

64

65

66

67

68

69

70

71

72

73

74

75

76

77

78

79

80

81

82

83

84

85

\section{Introduction}

Endosymbiosis between reef building corals and dinoflagellates assigned to the family Symbiodiniaceae (LaJeunesse et al. 2018) creates the foundation for one of the most diverse and productive marine ecosystems on the planet. However, this association is highly sensitive to rising seawater temperature. A rise of only $1 \sim 2{ }^{\circ} \mathrm{C}$ above the summer average under moderate to high irradiance will likely disrupt symbiotic relationships by causing the expulsion of symbionts from the host, resulting in so-called "coral bleaching" (Fitt et al. 2001; Lesser and Farrell 2004). Global warming enforces this impact by increasing the incidence of repeated beyond-threshold seawater temperatures, leading to more frequent coral bleaching events such as the devastating bleaching events that have occurred at the Great Barrier Reef in recent years (Hughes et al. 2018). Catastrophic impacts caused by global warming highlights the threat to coral survival, and thus evokes intensive attention on the mechanisms underpinning coral bleaching.

Despite coral bleaching having been intensively studied (reviewed in Weis [2008], Lesser [2011] and van Oppen and Lough [2018]), its mechanism(s) are still not well-understood. The main obstacles to uncovering these mechanisms are attributed to the high diversity in coral species and dynamic multiple partnerships among coral holobionts. Reef building corals are not only associated with intracellular photoautotrophs, but also a consortium of microorganisms including bacteria, archaea, viruses, fungi, and protists (van Oppen and Lough 2018). The coral holobiont functions as a unit to provide flexible stability when confronting environmental stressors. Therefore, it is necessary to approach coral bleaching from several aspects.

Accumulating data indicate that the main cause of coral bleaching might be attributed to the generation of reactive oxygen species (ROS) resulting from photoinhibition in Symbiodiniaceae algae and/or mitochondrial dysfunction in the coral host under thermal stress (Cziesielski et al. 2019). Bursts of ROS damage essential biomolecules and signals and mediate cellular termination processes such as apoptosis, autophagy, and cell necrosis (Weis 2008, Lesser 2011). However, some biotic factors are capable of mitigating coral bleaching. For example, associations with the Symbiodiniaceae algae Durusdinium trenchii or other thermal resistant species might elevate coral bleaching thresholds (Stat et al. 2011, Hsu et al. 2012, Howells et al. 2012, Silverstein et al. 2012, Keshavmurthy et al. 2014). The comparatively high resistance of Durusdinium algae to heat stress might be attributed to a high level of fatty acid saturation in membranes (Tchernov et al. 2004). In addition to algal symbiont factors, the role of coral hosts in resisting bleaching is also emphasized (Baird et al. 2009). After an intensive survey following a mass bleaching, Loya et al. (2001) proposed that the winners might be the massive and thick-tissue corals. Several lines of evidence also suggest that coral hosts could protect their symbiosis from heat bleaching by regulating photo-protective and/or antioxidant 
86 systems (Baird et al. 2009, Linan-Cabello et al. 2010), increasing heterotrophy (Grottoli et al. 87 2006), or controlling symbiont cell densities (Cunning et al. 2015). Coral hosts under heat stress 88 could also upregulate the expression of stress related genes (e.g., heat shock proteins and ROS 89 scavengers) (Barshis et al. 2013, Dixon et al. 2015, Kenkel et al. 2013, Palumbi et al. 2014) or 90 express a more thermal resistant respiration enzyme (e.g., malate dehydrogenase) (Wang et al. 91 2019).

Apart from the coral host and Symbiodiniaceae algae, growing evidence indicates that the coral-associating microbiome might contribute to coral health and resilience (reviewed by Bourne et al. 2016). A notable member of the core coral microbiome is affiliated with the

95

96 Endozoicomonas genus (Gammaproteobacteria class, Hahellaceae family), which can comprise as much as $90 \%$ of the microbiome and is associated with a wide range of coral species (Neave et al. 2017 and the references therein). Ecological and genetic evidence also suggest that Endozoicomonas might benefit coral health and fitness (Bourne et al., 2008, Neave et al. 2014, Ding et al. 2016). The roles of Endozoicomonas on thermal bleaching susceptibility in corals are controversial. Despite several studies suggested that high abundance of Endozoicomonas were usually found in the non-bleached corals after bleaching events (Bourne et al., 2008, Lee et al., 2015; Pantos et al., 2015; Glasl et al., 2016; Ziegler et al., 2017), some bleached corals were still associated with this microbial group (Pogoreutz et al. 2018, Shiu et al. 2020). Direct evidence to show the positive effect of associating microbiomes with coral bleaching was presented by inoculating a so-called probiotic microbiome consortium to Pocillopora, which partially mitigated coral bleaching from higher temperatures (Rosado et al. 2019). However, how long the coral will maintain the introduced bacteria and the mechanisms by which inoculated bacteria may mitigate coral bleaching are unclear and require further studying (Blackall et al. 2020).

To examine the roles of the coral host, algal symbionts, and associating bacteria, we applied herein an acute temperature treatment to test bleaching responses in two dominant coral species, Platygyra verweyi and Isopora palifera, in a natural mesocosm having seawater temperatures similar to forecasted 2050 ocean temperatures (Hsu et al. 2012; Kao et al. 2018). These species were selected due to their being Durusdinium trenchii-associated at our long-term monitoring site. This allowed us to compare the roles of coral hosts and their associated bacteria in their bleaching responses under the same algal symbiont to mimic the scenario of corals switching (or shuffling) to a thermal tolerant algal strain association following a thermal bleaching event.

\section{Materials and Methods}

\section{Sample collection, maintenance, and menthol bleaching}


122

123

124

125

126

127

128

129

130

131

132

133

134

135

136

137

138

139

140

141

142

143

144

145

146

147

148

149

150

151

152

153

154

155

156

157

Nubbins of $P$. verweyi and I. palifera corals were collected from tagged populations (Hsu et al. 2012, Kao et al. 2018) at a 3 m depth. Pingtung County Government and National Kenting National Park approved this research. The sampling site was located in a bay near the third nuclear power plant outlet (NPP-OL) in Kenting National Park, Taiwan (12044'13' 'E, 21 ${ }^{\circ} 56^{\prime} 4^{\prime}$ ' $\left.\mathrm{N}\right)$, within a zone that has been heated by power plant discharges since 1985 (Keshavmurthy et al. 2014). Surviving populations $P$. verweyi and $I$. palifera corals at NPP-OL have adapted to the higher temperature environment by associating with the thermal resistant Symbiodiniaceae alga Durusdinium trenchii (Hsu et al. 2012, Keshavmurthy et al. 2014, Kao et al. 2018) since at least a 2007 survey. Cladocopium sp. C1 associating coral Stylophora pistillata, which has disappeared from the shallow waters of NPP-OL (Keshavmurthy et al. 2014), was collected from below the hot water zone at 10-15 m depths at NPP-OL as the temperature sensitive reference. Collected coral nubbins were acclimated in a mesocosm aquarium as indicated in Wang et al. (2012) for one week to allow for wound healing prior to use.

Prior to determine the respiration breaking temperature (RBT) and fatty acid (FA) composition of the coral hosts, each of the approximately $3 \times 3 \mathrm{~cm}$ coral nubbins were bleached with 90 ppm menthol-supplemented artificial seawater (ASW) prepared from a sea salt mixture (Instant Ocean, Aquarium Systems, France) as previously described (Wang et al. 2012).

\section{Tissue thickness, RBT values, and fatty acid composition analyses}

Each of the approximately $2 \times 2 \mathrm{~cm} P$. verweyi and I. palifera nubbins was fixed in a $10 \%$ ASW-formalin solution, and then decalcified with 10\% acetic acid containing 5\% formalin for further tissue thickness measurement as described in Loya et al (2001).

Coral host RBT was measured following the method developed in Wang et al. (2019). Basically, the changes in respiration rate of a menthol-bleached coral nubbins were monitored in a respiration chamber under $2{ }^{\circ} \mathrm{C}$ incrementally increasing temperatures from $26 \sim 27{ }^{\circ} \mathrm{C}$ to $42 \sim$ $43{ }^{\circ} \mathrm{C}$. Oxygen content was measured with an optical dissolved oxygen instrument (YSI ProODO, USA) to avoid electrode polarization.

To determine the FA composition of coral host lipids, menthol-bleached coral nubbins were starved for a week to reduce stored lipids before subjecting to lyophilization. Freeze-dried coral tissue was collected by cutting off the part above the basal plate with a bone saw. Coral tissue lipids were extracted with 10 volumes of chloroform/methanol (2:1, containing $0.01 \% 2$,6-di-tertbutyl-4-methylphenol) at $4{ }^{\circ} \mathrm{C}$ overnight after powdering the tissue on the skeleton in liquid nitrogen with a mortar and pestle. Following dehydration, concentration by evaporation, and derivatization, methyl esterified FA was analyzed by gas chromatography. The degree of 
158 saturation of each FA was calculated from the ratio of percent saturated to all unsaturated 159 derivatives.

160

161

162

163

164

165

166

167

168

169

170

171

172

173

174

175

176

177

178

179

180

181

182

183

184

185

186

187

188

189

190

191

192

193

\section{Heat treatment, fluorescence methodology, and sample preparation}

Acute thermal challenging was used to compare the bleaching susceptibility of the two "thermal-adapted" coral species and a temperature-sensitive species. Heat treatment was conducted by transferring each of four coral nubbins (about $2 \times 2 \mathrm{~cm}$ or $5 \mathrm{~cm}$ branch) from three colony replicates of one species, a total of 12 coral nubbins, from $25{ }^{\circ} \mathrm{C}$ aquarium water directly into to a glass tank with $40 \mathrm{~L}$ pre-warmed $\left(31.0 \pm 0.5^{\circ} \mathrm{C}\right) \mathrm{ASW}$. Seawater in the heated tank was filtered through several layers of aquarium filter pad and a protein skimmer. Before introducing the next species, the tank was cleaned and its ASW replaced with fresh ASW and circulated for one day. Temperature and light fluctuation in the heating tank were recorded with HOBO Data Loggers (UA-001-64). An example of temperature and light conditions is shown in Fig. S1, in which one or two sudden drops in light intensity during the daytime occurred during a 30 min dark adaptation in preparation for quantum yield measurements on the coral specimens.

During heating, the maximum quantum yield of PSII $\left(F_{\mathrm{v}} / F_{\mathrm{m}}=\left[F_{\mathrm{m}}-F_{0}\right] / F_{\mathrm{m}}\right)$ of the coral nubbins were determined as described in Wang et al. (2011). At each time interval, one nubbin from each colony replicate was collected for preparing tissue homogenates by air/buffer blasting with $50 \mathrm{mM}$ phosphate buffer containing $0.1 \mathrm{mM}$ EDTA and $10 \%$ glycerol ( $\mathrm{pH} 7.0)$. After making up to $7 \mathrm{ml}$ with the above buffer, tissue homogenates were centrifuged at $4{ }^{\circ} \mathrm{C}(15,000 \mathrm{rpm})$ for 15 min to collect pellets for algal density measurement and supernatants to determine stress enzyme activity.

Separate sets of coral nubbins from the same colony replicates of $P$. verweyi and I. palifera were also treated in the heated tank for $24 \mathrm{~h}$, then washed twice with sterilized ASW and preserved in absolute ethanol at $-20^{\circ} \mathrm{C}$ for bacterial composition analysis.

\section{Algal density measurement and enzyme assay}

The numbers of collected Symbiodiniaceae cells were counted with a Neubauer improved hemocytometer as previously described (Wang et al. 2012), and coral surface areas were normalized according to the aluminum foil method.

Total superoxide dismutase (SOD) activity in coral tissue extracts was determined with a commercial kit (19160 SOD determination kit, Sigma-Aldrich, USA) following manufacturer instructions. The catalase (CAT) assay was modified from the spectrophotometric method described by Krueger et al. (2015). Briefly, $10 \mu \mathrm{l}$ host extract was added to $790 \mu 150 \mathrm{mM}$ 
194 phosphate buffer containing $0.1 \mathrm{mM}$ EDTA and $14 \mathrm{mM} \mathrm{H}_{2} \mathrm{O}_{2}(\mathrm{pH}$ 7.0) for measuring changes at $195240 \mathrm{~nm}$ absorbance, and finally converted to a $\mathrm{H}_{2} \mathrm{O}_{2}$ concentration having a molar coefficient of

196

197

198

199

200

201

202

203

204

205

206

207

208

209

210

211

212

213

214

215

216

217

218

219

220

221

222

223

224

225

226

227

228

229

43.6. All enzyme activity measurements were determined at $25{ }^{\circ} \mathrm{C}$ and standardized with the protein content in the extract as measured by a Bradford Assay (Bio-Rad Protein Assay, Bio-Rad) according to the manufacturer's protocol.

\section{Bacterial composition analysis}

Sequencing hypervariable regions V6-V8 of the 16S rRNA gene was used to examine bacterial composition in the corals. DNA extraction, PCR reaction, sequencing methodology, and data analysis followed the protocols described in Shiu et al. (2017). Briefly, bacterial particles in treated coral tissue were isolated by air/buffer blasting with $\times 10 \mathrm{TE}$ buffer and centrifugation $(10,000 \times \mathrm{g}, 15 \mathrm{~min})$. DNA was extracted by a modified CTAB method, and then subjected to PCR amplification by using two bacterial universal primers targeting the V6-V8 hypervariable region of the 16S rRNA gene: 968 F (5'-AACGCGAAGAACCTTAC-3') and Uni1391R (5'ACGGGCGGTGWGTRC-3'). After agarose electrophoresis, PCR amplicons of approximately $420 \mathrm{bp}$ were collected for further DNA tagging PCR amplification as developed by Chen et al. (2011). The resulting DNA samples from tagging PCR were then applied to Illumina MiSeq sequencing (Yourgene Bioscience, Taipei, Taiwan), and the raw sequencing data merged into paired-end reads using USEARCH v8.1.1861 (Edgar 2010).

To qualify sequence data, obtained reads were analyzed with Mothur v1.36.1 to retain the reads between 380 and $450 \mathrm{bp}$ with Phred quality score $>27$. Chimeric reads were then trimmed by UCHIME (Edgar et al. 2011) in USEARCH v7.0.1090 (parameters: reference mode, rdp_gold database, and mindiv of 5). Resulting non-chimeric reads were further analyzed with UPARSE pipeline (Edgar 2013) to generate OTUs (97\% identity level). The OTU classification was performed on a per sample basis using the SILVA v128 database with a pseudo-bootstrap cut-off of $80 \%$. Accession number to these SRA data is PRJNA736837: Bacterial diversity on Coral.

\section{Testing the contribution of Endozoicomonas to coral resistance to bleaching}

To test the benefit of Endozoicomonas to coral thermal resistance to bleaching, Endozoicomonas-associated $P$. verweyi nubbins were treated with antibiotics and nonEndozoicomonas-associated I. palifera were infected with E. montiporae following $31{ }^{\circ} \mathrm{C}$ heat challenging. Antibiotic treatment was conducted by incubating $P$. verweyi in well-aerated ASW containing $100 \mu \mathrm{g} \mathrm{ml}^{-1}$ nalidixic acid, $1 \mathrm{mg} \mathrm{ml}^{-1}$ ampicillin, and $50 \mu \mathrm{g} \mathrm{ml}^{-1}$ streptomycin for nine days at $25 \sim 26{ }^{\circ} \mathrm{C}$ under the same light-dark maintenance regime mentioned above. Antibiotic- 
230 supplemented seawater was prepared with sterilized ASW and changed daily. One set of

231 antibiotic-treated $P$. verweyi recovered in the maintenance aquarium (antibiotics free) for one

232 week as the control. The infection of I. palifera with Endozoicomonas was modified from the

233 method described in Rosado et al. (2019). Basically, Endozoicomonas was cultured to the log

234 phase in the medium developed by Ding et al. (2016), and then concentrated by centrifugation at

$23512,000 \mathrm{rpm}$ at $20^{\circ} \mathrm{C}$ for $10 \mathrm{~min}$, followed by adding ASW to make up a bacterial suspension

236 containing $10^{7} \sim 10^{8}$ cells ml $^{-1}$. To infect coral with Endozoicomonas, tested coral specimens

237 were placed in a dish of ASW with only the coral skeleton immersed, leaving coral tissue

238 exposed to the air. Then, $1 \mathrm{ml}$ of concentrated bacterial suspension was spread onto coral tissues

239 and allowed to stand for $10 \mathrm{~min}$, followed by adding $1.5 \mathrm{~L} \mathrm{ASW}$ into the dish for a further $2 \mathrm{~h}$ of

240 incubation under aeration. Spreading corals with ASW was used as a control. The infection

241 process was carried on for $2 \mathrm{~h}$ per day, and repeated for seven consecutive days. After infection,

242 coral samples were rinsed with fresh ASW and transferred back to the maintenance aquarium.

243 Endozoicomonas in coral tissues was detected by semi-quantitative PCR using mismatched

244 primer En771R designed by Shiu et al (2018) with $\beta$-actin gene as an internal reference. The

245 primer set (F: TTCCTTGGAATGGAATCTGC; R: GCGAAGTGATTTCTTTCTGC) used to

246 amply the $\beta$-actin gene was modified from Shiu et al. (2020), and produces a $163 \mathrm{bp}$ DNA

247 fragment. Due to intensive algal symbiont loss occurring in I. palifera when treated with $31^{\circ} \mathrm{C}$

$24824 \mathrm{~h}$, amplification of the bacterial 16S ribosomal RNA gene was conducted to confirm DNA

249 extraction efficiency following the method described in Chen et al. (2011). Heat challenging and

250 monitoring the indicators of stress and bleaching were conducted as described above.

251

252

Statistical analysis

253

254 Data in this study are presented as means \pm S.D., with at least three colony replicates.

255 Comparisons of enzyme activity between different incubation times were made using a one-way

256 analysis of variance (ANOVA) followed by Tukey's post hoc analysis for multiple comparisons

257 at a significance level of 0.05 . The differences between two tested species or between treatments

258 within the same species were analyzed with a $t$-test. To reveal the differences in FA composition

259 between the two tested species, a principal component analysis (PCA) was conducted. The

260 similarity of $\gamma$-proteobacteria composition between the two coral species was analyzed with arc

261 cosine-transformed relative abundance of the identified genus by multidimensional scaling

262 (MDS) ordination (Kruskal and Wish 1978), followed by an analysis of similarity (ANOSIM)

263 (Clarke and Warwick 1994) using PRIMER 6 (Clarke and Warwick 1994).

264

265 Results 
Responses in photosynthesis and algal density to acute thermal stress

268

269

When coral nubbins were transferred directly from 25 to $31^{\circ} \mathrm{C}$, the maximum quantum yield of

270 $P$. verweyi remained stable at $>0.610$ throughout $72 \mathrm{~h}$ of heat treatment, but that of I. palifera

271 bumped up and down between 0.514 and 0.606 between 8 and $32 \mathrm{~h}$ and then declined to about

272 0.340 after $48 \mathrm{~h}$ incubation (Fig. 1). Temperature-sensitive $S$. pistillata, as predicted, displayed a

273

274

275

276

277

278

279

280

281

282

283

284

285

286

287

288

289

290

291

292

293

294

295

296

297

298

299

300

301 dramatic decrease in maximum quantum yield from about 0.660 to 0.170 within $24 \mathrm{~h}$. Consistent with the performance in maximum quantum yield, the algal density of $P$. verweyi remained stable $\left(2.6 \sim 3.5 \times 10^{6}\right.$ cells $\left.\mathrm{cm}^{-2}\right)$ throughout $72 \mathrm{~h}$ of heat treatment. Conversely, the algal density of $I$. palifera and $S$. pistillata declined dramatically from $1.6 \pm 0.3 \times 10^{6}$ and $1.0 \pm 0.0 \times$ $10^{6}$ cells cm $\mathrm{cm}^{-2}$ to $2.0 \pm 0.9 \times 10^{5}$ and $1.1 \pm 0.3 \times 10^{5} \mathrm{cells} \mathrm{cm}^{-2}$ with the $24 \mathrm{~h}$ heat treatment, respectively. In summary, incubation at $31{ }^{\circ} \mathrm{C}$ caused the loss of $87 \pm 8 \%$ and $89 \pm 3 \%$ algal symbionts in I. palifera and S. pistillata within 24 h, respectively.

\section{Tissue thickness and physio-biochemical performance}

To investigate why the two "thermal adapted" and Durusdinium-associated coral species, $P$. verweyi and I. palifera, displayed distinctly different bleaching susceptibility to acute thermal stress at $31^{\circ} \mathrm{C}$, several indictors known to highly correlate with coral bleaching were examined. Tissue thickness measurements indicated no difference between the two species $(P>0.05)$, which were $2.8 \pm 0.4 \mathrm{~mm}$ for $P$. verweyi and $3.0 \pm 0.2 \mathrm{~mm}$ for I. palifera. Respiration responses to rising temperature, expressed as RBT as described in Wang et al. (2019), also showed no difference between two species $(\mathrm{P}>0.05)$, which were $35.5 \pm 0.6^{\circ} \mathrm{C}$ for $P$. verweyi and $36.0 \pm$ $0.5^{\circ} \mathrm{C}$ for I. palifera.

FA composition in menthol-bleached and starved coral tissue of the two coral species indicated that, as shown in Fig. S2, more than 1/3 of the FA were dominated by myristic acid (14:0, Platygyra: $17.2 \pm 9.5 \%$; Isopora: $15.9 \pm 4.3 \%)$ and palmitic acid (16:0, Platygyra: $17.0 \pm$ 5.2\%; Isopora: $26.1 \pm 1.9 \%$ ). Platygyra also contained one more dominant FA, behenic acid $(22: 0,14.0 \pm 1.5 \%)$. The differences in FA composition between the two coral species were further examined by principal component analysis, in which $>95 \%$ of the variance in the dataset could be accounted for by the first two principal components (PC) (Fig. 2A). As shown in Fig. $2 \mathrm{~A}$, the PC1, accounting for $62.1 \%$ of the variance, divided the data into two groups in which $P$. verweyi was majorly accounted for by containing a higher percentage of two saturated FA (behenic acid and myristic acid). In contrast, PC1 indicated I. palifera contained a higher percentage of a short chain FA, palmitic acid, and a long chain unsaturated FA, erucic acid 
302 (22:1). The PC2, accounting for 33.9\% of the variance, was highly correlated with the relative 303 percentage of myristic acid in the coral host. When comparing FA in groups, $P$. verweyi

304

305

306

307

308

309

310

311

312

313

314

315

316

317

318

319

320

321

322

323

324

325

326

327

328

329

330

331

332

333

334

335

336

337 displayed significantly higher saturated $(\mathrm{P}<0.05)$ and lower mono-unsaturated FA $(\mathrm{P}<0.01)$ than I. palifera, but the two species showed no significant differences in poly-unsaturated FA (Table S1). Further, to examine the degree of saturation of each FA longer than $\mathrm{C} 14$ indicated (Fig. 2B), both coral species displayed comparable and high saturation levels (saturated/unsaturated: $10 \sim 40)$ in short chain FA (C14, C15, and C16), but low and varied saturation levels $(0.3 \sim 3.4)$ in long chain FA (C18, C20, C22, and C24). Moreover, the degrees of saturation in $\mathrm{C} 18$ and $\mathrm{C} 22$ of $P$. verweyi FA were significantly higher than in I. palifera $(\mathrm{P}<$ 0.05), and in $\mathrm{C} 22$ of $P$. verweyi were about 12-fold higher than in I. palifera.

The activity of antioxidant enzymes SOD and CAT in the heat-treated corals were also examined. Given that part of the I. palifera samples were completely bleached after $24 \mathrm{~h}$ at 31 ${ }^{\circ} \mathrm{C}$, the determination of enzyme activity in this species was conducted only with the samples under $24 \mathrm{~h}$ incubation. SOD activity in both coral species indicated that enzyme activity varied between incubation times $(\mathrm{P}<0.05)$. As indicated in Fig. 3(A), P. verweyi had stable SOD activity at about $100 \mathrm{U} \mathrm{mg}^{-1}$ within $48 \mathrm{~h}$ at $31^{\circ} \mathrm{C}$, and then significantly increased to $181 \pm 51 \mathrm{U}$ $\mathrm{mg}^{-1}$ at $72 \mathrm{~h}$ of treatment $(\mathrm{P}<0.05)$. I. palifera contained $<10 \% \mathrm{SOD}$ of that of $P$. verweyi $(\mathrm{P}<$ 0.01). In response to heat treatment, both coral species significantly doubled their SOD activity at different time regimes $(\mathrm{P}<0.05)$, which occurred at $24 \mathrm{~h}$ and $72 \mathrm{~h}$ of heat treatment for $I$. palifera and $P$. verweyi, respectively. While CAT analysis indicated that enzyme activity in both coral species did not significantly vary between incubation times $(\mathrm{P}>0.05), P$. verweyi displayed nearly $3 \times$ higher CAT activity than I. palifera $(\mathrm{P}<0.01)$ (Fig. 3B).

\section{Composition of the bacterial community}

Bacterial composition in $P$. verweyi and I. palifera before and after $24 \mathrm{~h}$ of heating at $31^{\circ} \mathrm{C}$ was also analyzed. The non-chimera reads of all but one of the samples ranged from 13,698 to 78,839 (37,257 on average). Only one sample from heat-treated colony 1 of I. palifera showed a low read of 2,909. Excluded chimera reads in all samples were $<5 \%$ (2.4\% on average). Total identified OTUs were 2,037, in which 1,955 OTUs were classified as bacteria. Composition analysis indicated that both species before and after $24 \mathrm{~h}$ heating were dominated $(>85 \%)$ by Proteobacteria (Fig. S3). At the class level, both coral species were consistently dominated by $\gamma$ and $\alpha$-proteobacteria, but before-heated $P$. verweyi contained significantly more $\gamma$-proteobacteria $(84.4 \pm 1.7 \%)$ and less $\alpha$-proteobacteria $(10.0 \pm 1.7 \%)$ than the corresponding I. palifera $(56.2 \pm$ $13.8 \% \gamma$-proteobacteria and $28.9 \pm 5.9 \% \alpha$-proteobacteria; $\mathrm{P}<0.05$; Fig. S4). Heating at $31{ }^{\circ} \mathrm{C}$ for $24 \mathrm{~h}$ did not change the dominance of $\gamma$ - and $\alpha$-proteobacteria in both species $(\mathrm{P}>0.05$; Fig. 
338 S4). When comparing $\gamma$-proteobacteria composition between the two coral species (Fig. 4), the 339 MDS plot indicated that, before and after heating, bacterial composition in $P$. verweyi was 340 completely different from I. palifera (ANOSIM, P =0.002). Also, no significant changes in $\gamma-$ 341 proteobacteria composition were found in corals with $24 \mathrm{~h}$ heat treatment (Fig. 4), except for the 342 colony 1 of heat-treated I. palifera.

$343 \quad$ More than $50 \%(59.7 \pm 2.9 \%$ for before-heating and $62.7 \pm 14.3 \%$ for after-heating 344 samples) of the genera of $\gamma$-proteobacteria in $P$. verweyi were indicated (Fig. 5) to be 345 Endozoicomonas, but the latter's relative abundance in I. palifera was low $(<2.0 \%$ for before-

346

347

348

349

350

351

352

353

354

355

356

357

358

359

360

361

362

363

364

365

366

367

368

369

370

371

372 heating and $<0.1 \%$ for after-heating). Moreover, heating for $24 \mathrm{~h}$ did not change the relative abundance of Endozoicomonas in P. verweyi. The most dominant $\gamma$-proteobacteria in I. palifera was $\gamma$-proteobacteria/unclassified, which, however, varied among colony replicates during heat treatment. The relative abundance of $\gamma$-proteobacteria/unclassified of colonies 1 and 2 decreased from $21.7 \sim 32.6 \%$ to $0.7 \sim 8.2 \%$ after heating, but colony 3 displayed a slight increase from $14.5 \%$ to $19.0 \%$. A huge increase in the relative abundance of Vibrio was found in colony 1 of $I$. palifera after heating, increasing from 1.0 to $64.7 \%$, while the relative abundance of Vibrio in heated colonies 2 and 3 remained at low levels, increasing only from $0.2 \sim 0.7 \%$ to $0.6 \sim 3.6 \%$. Note that unusually high relative-abundance of Vibrio, low non-chimera reads and manifesting as an outgroup in the MDS analysis were all came from the heat treated colony 1 of I. palifera.

\section{Thermal tolerance of corals with the manually altered Endozoicomonas association}

When $P$. verweyi was treated with antibiotics for nine days, only the replicates from colony 2 at $31^{\circ} \mathrm{C} / 48 \mathrm{~h}$ showed no Endozoicomonas detection (Fig. S5B); however, total bacterial counts in their coral tissue extracts were reduced by more than $80 \%$. The attempted inoculation of $E$. montiporae in I. palifera resulted in no positive infection in most colony replicates, except those from colony 2 at $31{ }^{\circ} \mathrm{C} / 24 \mathrm{~h}, / 48 \mathrm{~h}$, and $/ 72 \mathrm{~h}$ (Fig. S5C). When subjecting treated corals to $31{ }^{\circ} \mathrm{C}$ (Table 1) both the antibiotic-treated $P$. verweyi and those recovering from antibiotic treatment displayed no significant changes in algal density after $72 \mathrm{~h}$ incubation, compared with pre-treated and $25^{\circ} \mathrm{C}$ treated controls $(\mathrm{P}>0.05)$. Table 1 also indicates that, with or without E. montiporae infection, I. palifera displayed a significant decrease in algal density from $(2.3 \pm 1.2) \times 10^{6} \mathrm{~cm}^{-2}$ to $(6.7 \pm 2.6) \times 10^{4} \mathrm{~cm}^{-2}$ for Endozoicomonas infection and $(6.6 \pm 8.6) \times 10^{5} \mathrm{~cm}^{-2}$ for no $E$.

montiporae infection when incubated at $31{ }^{\circ} \mathrm{C}$ for $72 \mathrm{~h}$.

\section{Discussion}


373 This study indicates that coral hosts might require extra high antioxidant enzyme activity to

374 counteract acute thermal stress, even when already associated with thermal resistant algal

375 symbionts. In Kenting, southern Taiwan, a nuclear power plant along the western side of

376 Nanwan Bay has continuously discharged hot water into ambient seawater since 1984. Part of

377 the heated seawater is trapped in a bay on the west side of the nuclear power plant outlet (NPP-

378 OL) because of a near-shore current and tides (Chiou et al. 1993), which elevate average

379 seawater temperatures $2.0 \sim 3.0^{\circ} \mathrm{C}$ higher than at other coral reef sites in Kenting (Fan 1991,

380 Pier 2011, also see Keshavmurthy et al. 2012). The hot water discharged in this area has

381

382

383

384

385

386

387

388

389

390

391

392

393

394

395

396

397

398

399

400

401

402

403

404

405

406

407

408 impacted the marine ecology within the area (Chiou et al.1993, Hung et al. 1998, Jan et al. 2001, Hwang et al. 2004). After more than 30 years of regular hot water influx and exposure to several instances of heatwaves, the coral community at NPP-OL has dramatically changed and lost almost all branch coral species from its shallow waters (Keshavmurthy et al. 2014). The remaining "thermal adapted" coral species in those shallows display constant associations with thermal resistant algal genotypes such as D. trenchii or Cladocopium sp. (C15) (Keshavmurthy et al. 2014). Unexpectedly, this study found that two "thermal adapted" and D. trenchiiassociating coral species, $P$. verweyi and I. palifera, display distinctly higher bleaching resistant capability in former species than the latter one when confronted with acute thermal stress (Fig. 1B). The performance of Isopora on thermal bleaching might be different from that in Fig. 1B, if treated with slowly heating. However, even treated with a sudden rising of seawater temperature to $31^{\circ} \mathrm{C}$, Platygyra displayed no algal loss (Fig. 1B). This finding indicated Platygyra might have certain thermal resistant characteristics, which not found in Isopora. Due to both corals harboring the same symbiont strain, this phenomenon might not be derived from the performance of algal symbiont. High maximum quantum yield in bleaching Isopora after $32 \mathrm{~h}$ of heat treatment (Fig. 1A) partially supported this statement. Therefore, this study focused on characterizing the differences in coral hosts.

Coral tissue thickness indicates that both coral species belong to the thick-tissue group, consistent with other coral species prone to higher survivorship after thermal bleaching as indicated by Loya et al. (2001). The respiration response to temperature (RBT) also indicates that both species might have similar acclimatization temperatures, which is consistent with their habitat environment (Wang et al. 2019). However, none of these explanations explain the distinctly different performance in acute thermal response between the two species. The differences between $P$. verweyi and I. palifera hosts showed in FA composition, antioxidant enzymes, and microbiome composition, any or all of which could directly or indirectly account for their distinctly different bleaching responses to acute thermal stress.

The FA analyses of menthol-bleached $P$. verweyi and I. palifera displayed two separate compositions, both of which were lacking in typical alga-derived polyunsaturated fatty acids 
409 (i.e., C18:4, C22:5, and C22:6), which are markers of algal symbiosis (Papina et al. 2003),

410 indicating that their FA compositions were solely derived from the coral hosts. Consistent with

411 the more thermal tolerant response in $P$. verweyi, this coral displayed significantly higher

412 saturated and lower mono-unsaturated FA than I. palifera. Moreover, the FA composition of $P$.

413 verweyi was also dominated $(14.0 \pm 1.5 \%)$ by a long-chain saturated FA (C22:0), in which it was

$4144 \times$ more abundant than in I. palifera. FA became more saturated and contained longer carbon

415 chains in thermal tolerant $P$. verweyi, which coincided with remodeling of membrane lipids at

416 higher temperatures by adjusting FA composition to compensate for membrane fluidity. This is a

417 typical response of a membrane to rising temperature, known as homeoviscous adaptation (HVS)

418 (Sinensky, 1974). A similar adjustment in FA composition in response to temperature was also

419 found in Symbiodiniaceae algae (Tchernov et al. 2004) and the giant clam (Dubousquet et al.

420 2016). The unusually high abundance of behenic acid (C22:0) in $P$. verweyi is worthy of further

421 study to explore the effect of long chain saturated FA on coral membrane stability and its

422 contribution to mitigate coral bleaching under heat stress.

423 To investigate the role of the coral host on reducing coral bleaching stress, Baird et al.

424 (2009) summarized five potential mechanisms, including constitutive photoprotective

425

426

427

428

429

430

431

432

433

434

435

436

437

438

439

440

441

442

443

444

components, antioxidant systems, heat shock proteins, and shifting from heterotrophic feeding to gain energy. Except for adjusting the energy source, all efforts by coral hosts to alleviate thermal bleaching come down to reducing oxidation stress. In this study, we did not examine the production of heat shock protein in both species. However, $P$. verweyi was found to contain several-fold higher antioxidant enzyme activity (SOD and CAT) than I. palifera before and during heat treatment. Especially, enzyme activity before heat treatment had about 14 times higher SOD $\left(97 \pm 11 \mathrm{Umg}^{-1}\right)$ and 3 times higher CAT $\left(1,536 \pm 405 \mu \mathrm{mol} \mathrm{mg}^{-1} \mathrm{~min}^{-1}\right)$ in $P$. verweyi than in I. palifera (SOD: $7 \pm 1 \mathrm{Umg}^{-1}$ and CAT: $590 \pm 112 \mu \mathrm{mol} \mathrm{mg}^{-1} \mathrm{~min}^{-1}$ ). The function of SOD in the anti-oxidation process is to convert reactive oxygen species superoxide $\left(\mathrm{O}_{2}{ }^{-1}\right)$ to $\mathrm{H}_{2} \mathrm{O}_{2}$, followed by decomposing to $\mathrm{H}_{2} \mathrm{O}$ and $\mathrm{O}_{2}$ by CAT (Lesser 2006). Extra high constitutive SOD in $P$. verweyi suggests that these corals, after harboring thermal-tolerant algal symbionts adapted to the warmer habitat at NPP-OL, had also built up an efficient primary defense system against temperature-induced oxidative stress. The high SOD activity in $P$. verweyi from NPP-OL was obviously stimulated by high and fluctuating temperatures, because the same coral species from a nearby and temperature stable location, Wanlitong, contained levels of SOD (11 $\pm 3 \mathrm{Umg}^{-1}$, unpublished data) that were comparable to those of I. palifera in this study. Evidence of the adaption of $P$. verweyi to high and fluctuating NPP-OL was also found in this coral's key respiration enzyme, malate dehydrogenase (Wang et al. 2019). In contrast to $P$. verweyi, I. palifera seemed to only replace its temperature sensitive algal symbiont with a more temperature resistant one. Further study is needed to determine whether it is a faster

Peer] reviewing PDF | (2021:06:61888:4:0:NEW 9 Dec 2021) 
445 evolution rate or higher phenotypic plasticity that confers upon $P$. verweyi more adaptability to 446 higher and fluctuating temperature habitats.

$447 \quad P$. verweyi also displayed a consistent association with the coral symbiotic micro-organism

448 Endozoicomonas at a relatively high $(>1 / 3)$ abundance of total bacterial population; this was not 449 found in I. palifera. However, depleting Endozoicomonas from $P$. verweyi with antibiotics did 450 not abolish the coral's capability to resist bleaching at $31{ }^{\circ} \mathrm{C}$, and also did not change ROS and 451 CAT activities significantly. Because $>80 \%$ of the bacterial counts of $P$. verweyi had been 452 depleted with Endozoicomonas-sensitive antibiotics (Yang et al. 2010, Sheu et al. 2017, Chen et

453

454

455

456

457

458

459

460

461

462

463

464

465

466

467

468

469

470

471

472

473

474

475

476

477

478

479

480 al. 2019), corals retaining their bleaching-resistance capability at $31{ }^{\circ} \mathrm{C}$ likely was not due to invalid antibiotic treatment. Endozoicomonas-positive detection by PCR examination (Fig. S5A) might be derived from DNA residues of the bacterium in coral tissue. Directly inoculating cultured E. montiporae to I. palifera was barely successful. However, even when successfully infected with E. montiporae, I. palifera still displayed significant bleaching after $24 \mathrm{~h}$ at $31^{\circ} \mathrm{C}$. Besides E. montiporae, infection tests were also conducted with E. acroporae (Sheu et al. 2017) and E. coralli (Chen et al. 2019), with the same results as those from E. montiporae (unpublished data). The failure to infect I. palifera with Endozoicomonas might be attributed to host specificity (Ding et al. 2016, Neave et al. 2017), but high variability in seasonal microbial partnerships in I. palifera (Chen et al. 2011) also suggests that these corals might not be able to establish stable associations with certain bacterial strains as do other corals (Neave et al. 2017, Pogoreutz et al. 2018).

Endozoicomonas are generally assumed to be essential in coral holobiont functioning due to their widespread prevalence and high abundance in many coral species (Bayer et al. 2013, Jessen et al. 2013, Meyer et al. 2016, Glasl et al. 2016, Neave et al. 2016, Gignoux-Wolfsohn et al. 2017, Neave et al. 2017) and apparent metabolic versatility (Yang et al. 2010, Hyun et al. 2014, Ding et al. 2016, Neave et al. 2017). Reductions in the abundance of Endozoicomonas in stressed, diseased, or bleached corals were also reported in a number of studies, suggesting that the pervasive abundance of Endozoicomonas might be closely linked to a healthy status in corals (Bourne et al., 2008; Cárdenas et al., 2012; Gignoux-Wolfsohn et al., 2017; Meyer et al., 2016; Morrow et al., 2014; Roder et al., 2015; Röthig et al., 2016; Ziegler et al., 2016). However, some coral species seem to form more obligate associations with Endozoicomonas, even under different stresses (Sharp et al. 2017, Pogoreutz et al. 2018, Shiu et al. 2020). P. verweyi, as revealed in this study, also displayed a constant association with Endozoicomonas; however, a reduction in Endozoicomonas abundance did not impair symbiosis between Symbiodiniaceae algae and the coral even when heated at $31^{\circ} \mathrm{C}$. Endozoicomonas, unlike Symbiodiniaceae algae residing in coral cells, forms cell aggregates in coral tissues (Bayer et al. 2013). Therefore, it is reasonable to expect that Symbiodiniaceae algae and Endozoicomonas may undergo different 
481 evolutionary tracks to form symbioses with coral, and may have separate interactions with their

482 host even though both symbionts are altogether beneficial to the host.

483

484

\section{Conclusion}

485

486

In summary, rising temperatures drove coral species at NPP-OL to associate with thermalresistant symbiont strains, but the modification in coral hosts for adapting to the high

487 temperature environment was to diversify between species. Our results imply that bleaching

488

489

490

491

492

493

494

495

496

497

498

499

500

501

502

503

504

505

506

507

508

509

510

511

512

513

514

resistance might be upgraded by having more-saturated FA in coral membrane lipids and especially extra high coral SOD activity, which would benefit future attempts on assisted evolution in coral restoration. Coral symbiotic bacteria like Endozoicomonas are believed to play important roles on coral survivorship under stress, but their contributions might be indirect.

\section{Acknowledgement}

The authors would like to thank members of the Coral Reef Evolutionary Ecology and Genetics (CREEG) Group, Biodiversity Research Center, Academia Sinica (BRCAS), for field support, Prof. Youk-Meng Choong for fatty acid analysis, Prof. Win-Ming Chen for providing Endozoicomonas culture, and Buford Pruitt for English editing. This work was supported by grants from Ministry of Science and Technology (MOST 107-2621-B-127-001 and MOST 1082621-B-127-001) to JTW.

\section{References}

Baird AH, Bhagooli R, Ralph PJ, Takahashi S (2009) Coral bleaching: the role of the host. Trends Ecol Evol 24:16-20.

Barshis DJ, Ladner JT, Oliver TA, Seneca FO, Traylor-Knowles N, Palumbi SR (2013) Genomic basis for coral resilience to climate change. Proc Natl Acad Sci USA 110:1387-1392.

Bayer T, Neave MJ, Alsheikh-Hussain A, Aranda, M, Yum LK, Mincer T, Hughen K, Apprill A, Voolstra CR (2013) The microbiome of the red sea coral Stylophora pistillata is dominated by tissue-associated Endozoicomonas bacteria. Appl. Environ. Microbiol. 79:4759-4762.

Blackall LL, Dungan AM, Hartman LM, van Oppen MJH (2020) Probiotics for corals. Microbiology Australia 41:100-104.

Bourne D, Iida Y, Uthicke S. Smith-Keune C (2008) Changes in coral-associated microbial communities during a bleaching event. ISME J 2:350-363.

Bourne DG, Morrow KM, Webster NS (2016) Insights into the coral microbiome: underpinning the health and resilience of reef ecosystems. Annu Rev Microbiol 70:317-340. 
515 Cárdenas A, Rodriguez-R LM, Pizarro V, Cadavid LF, Arévalo-Ferro C (2012) Shifts in

516 bacterial communities of two Caribbean reef-building coral species affected by white plague 517 disease. ISME J. 6:502-512.

518 Chen CP, Tseng CH, Chen CA, Tang SL (2011) The dynamics of microbial partnerships in the 519 coral Isopora palifera. ISME J 5:728-740.

520 Chen W, Lin K, Sheu S (2019) Endozoicomonas coralli sp. nov., isolated from the 521 coral Acropora sp.. Arch Microbiol 201:531-538.

522 Chiou WD, Cheng LZ, Ou HC (1993) Relationship between the dispersion of thermal effluent

523 and the tidal current in the waters near the outlet of the third nuclear power plant in southern 524 Taiwan. J Fisheries Soc Taiwan 20:207-220.

525 Clarke KR, Warwick RM (1994) Changes in marine communities: an approach to statistical 526 analysis and interpretation.

527 Cunning R, Vaughan N, Gillette P, Capo TR, Maté JL, Baker AC (2015) Dynamic regulation of 528 partner abundance mediates response of reef coral symbioses to environmental change.

529 Ecology 96:1411-1420.

530 Cziesielski MJ, Schmidt-Roach S, Aranda M (2019) The past, present, and future of coral heat 531 stress studies. Ecol Evol 9:10055-10066.

532 Ding J-Y, Shiu J-H, Chen W-M, Chiang Y-R and Tang S-L (2016) Genomic Insight into the

533

534

535

536

537

538

539

540

541

542

543

544

545

546

547

548

549

550

Host-Endosymbiont Relationship of Endozoicomonas montiporae CL-33 ${ }^{\mathrm{T}}$ with its Coral Host. Front. Microbiol. 7:251.

Dixon GB, Davies SW, Aglyamova GA, Meyer E, Bay LK, Matz MV (2015) Genomic

determinants of coral heat tolerance across latitudes. Science 348:1460-1462.

Dubousquet V, Gros E, Berteaux-Lecellier V, Viguier B, Raharivelomanana P, Bertrand C, Lecellier GJ (2016) Changes in fatty acid composition in the giant clam Tridacna maxima in response to thermal stress. Biol Open 5:1400-1407.

Edgar, R. C. (2010). Search and clustering orders of magnitude faster than BLAST. Bioinformatics 26:2460-2461.

Edgar RC, Haas BJ, Clemente JC, Quince C, Knight R (2011) UCHIME improves sensitivity and speed of chimera detection. Bioinformatics 27:2194-2200.

Edgar RC (2013) UPARSE: highly accurate OTU sequences from microbial amplicon reads. Nat Methods 10:996-998.

Fan KL (1991) The thermal effluent problems of three nuclear power plants in Taiwan. In:

Takano K, ed. Oceanography of Asian marginal seas, 54. Amsterdam: Elsevier Oceanography Series, pp. 393-403.

Fitt WK, Brown BE, Warner ME, Dunne RP (2001) Coral bleaching: interpretation of thermal tolerance limits and thermal thresholds in tropical corals. Coral Reefs 20:51-65.

Peer] reviewing PDF | (2021:06:61888:4:0:NEW 9 Dec 2021) 
551 Furla P, Galgani I, Durand I, Allemand D (2000) Sources and mechanisms of inorganic carbon 552 transport for coral calcification and photosynthesis. J Exp Biol 203:3445-3457.

553 Gignoux-Wolfsohn SA, Aronson FM, \& Vollmer SV (2017) Complex interactions between

554 potentially pathogenic, opportunistic, and resident bacteria emerge during infection on a reef-

555 building coral. FEMS Microbiol. Ecol. 93:fix080.

556 Glasl B, Herndl GJ, Frade PR (2016) The microbiome of coral surface mucus has a key role in

557 mediating holobiont health and survival upon disturbance. ISME J. 10:2280-2292.

558 Grottoli AG, Rodrigues LJ, Palardy JE (2006) Heterotrophic plasticity and resilience in bleached 559 corals. Nature 440:1186-1189.

560 Howells EJ, Beltran VH, Larsen NW, Bay LK, Willis BL, van Oppen MJH (2012) Coral thermal 561 tolerance shaped by local adaptation of photosymbionts. Nat Clim Change 2: 116-120.

562 Hsu C-M, Keshavmurthy S, Denis V, Kuo C-Y, Wang J-T, Meng P-J, Chen CA (2012)

563 Temporal and spatial variations in symbiont communities of catch bowl coral Isopora palifera 564 (Scleractinia: Acroporidae) on Reefs in Kenting National Park, Taiwan. Zool Stud 51:13435651353.

566 Hung T-C, Huang C-C, Shao K-T. 1998. Ecological survey of coastal water adjacent to nuclear 567 power plants in Taiwan. Chemistry and Ecology 15:129-142.

568 Hughes TP, Kerry JT, Baird AH, Connolly SR, Dietzel A, Eakin CM, Heron SF, Hoey AS, 569 Hoogenboom MO, Liu G, McWilliam MJ, Pears RJ, Pratchett MS, Skirving WJ, Stella JS, 570 Torda G (2018) Global warming transforms coral reef assemblages. Nature 556:492-496.

571 Hwang R-L, Tsai C-C, Lee T-M. 2004. Assessment of temperature and nutrient limitation on 572 seasonal dynamics among species of Sargassum from a coral reef in southern Taiwan. $J$ 573 Phycol 40:463-473.

574 Hyun DW, Shin NR, Kim MS, Oh SJ, Kim PS, Whon TW, Bae JW (2014) Endozoicomonas 575 atrinae sp. nov., isolated from the intestine of a comb pen shell Atrina pectinata. ISME J. $576 \quad 64: 2312-2318$.

577 Jan R-Q, Chen J-P, Lin C-Y, Shao K-T (2001) Long-term monitoring of the coral reef fish 578 communities around a nuclear power plant. Aquatic Ecology 35:233-243.

579 Jessen C, Villa Lizcano JF, Bayer T, Roder C, Aranda M, Wild C, Voolstra CR (2013) In-situ 580 effects of eutrophication and overfishing on physiology and bacterial diversity of the Red Sea 581 coral Acropora hemprichii. PLoS ONE 8:e62091.

582 Kao KW, Keshavmurthy S, Tsao CH, Wang JT, Chen CA (2018) Repeated and prolonged 583 temperature anomalies negate Symbiodiniaceae genera shuffling in the coral Platygyra 584 verweyi (Scleractinia; Merulinidae). Zool Stud 57:55. 
585 Kenkel C, Meyer E, Matz M (2013) Gene expression under chronic heat stress in populations of

586

587

588

589

590

591

592

593

594

595

596

597

598

599

600

601

602

603

604

605

606

607

608

609

610

611

612

613

614

615

616

617

618

619 the mustard hill coral (Porites astreoides) from different thermal environments. Mol Ecol 22:4322-4334.

Keshavmurthy S, Meng P-J, Wang J-T, Kuo CY, Yang SY, Hsu CM, Gan CH, Dai CF, Chen CA (2014) Can resistant coral-Symbiodinium associations enable coral communities to survive climate change? A study of a site exposed to long-term hot water input. PeerJ 2:e327.

Krueger T, Hawkins TD, Becker S, Pontasch S (2015) Differential coral bleaching: Contrasting the activity and response of enzymatic antioxidants in symbiotic partners under thermal stress. Comp. Biochem. Physiol. Part A 190:15-25.

Kruskal JB, Wish M (1978) Multidimensional scaling.

LaJeunesse TD, Parkinson JE, Gabrielson PW, Jeong HJ, Reimer JD, Voolstra CR, Santos SR (2018) Systematic revision of Symbiodiniaceae highlights the antiquity and diversity of coral endosymbionts. Curr Biol 28:1-11.

Lee ST, Davy SK, Tang SL, Fan TY, Kench PS (2015) Successive shifts in the microbial community of the surface mucus layer and tissues of the coral Acropora muricata under thermal stress. FEMS Microbiol. Ecol. 91:fiv142.

Lesser MP, Farrell JH (2004) Exposure to solar radiation increases damage to both host tissues and algal symbionts of corals during thermal stress. Coral Reefs 23:367-377.

Lesser MP (2006) Oxidative stress in marine environments: biochemistry and physiological ecology. Annu Rev Physiol. 68:253- 278.

Lesser MP (2011) Coral Bleaching: Causes and Mechanisms. In: Dubinsky Z., Stambler N. (eds) Coral Reefs: An Ecosystem in Transition. Springer, Dordrecht.

Linan-Cabello MA, Flores-Ramirez LA, Zenteno-Savin T, Olguín-Monroy NO, Sosa-Avalos R, Patiño-Barragan M, Olivos-Ortiz A (2010) Seasonal changes of antioxidant and oxidative parameters in the coral Pocillopora capitata on the Pacific coast of Mexico. Mar Ecol. 31:407-417.

Loya Y, Sakai K, Yamazato K, Nakano Y, Sambali H, van Woesik R (2001) Coral bleaching: the winners and the losers. Ecol Lett 4:122-131.

Meyer JL, Gunasekera SP, Scott RM, Paul VJ, \& Teplitski M (2016) Microbiome shifts and the inhibition of quorum sensing by Black Band Disease cyanobacteria. ISME J. 10:1204-1216.

Morrow KM, Bourne DG, Humphrey C, Botté ES, Laffy P, Zaneveld J, Uthicke S, Fabricius KE, Webster NS (2014) Natural volcanic $\mathrm{CO}_{2}$ seeps reveal future trajectories for host-microbial associations in corals and sponges. ISME J. 9:894-908.

Neave MJ, Michell CT, Apprill A, Voolstra CR (2014) Whole-genome sequences of three symbiotic Endozoicomonas strains. Genome Announc 2:e00802-14. 
620 Neave MJ, Apprill A, Ferrier-Pagès C, \& Voolstra CR (2016) Diversity and function of

621 prevalent symbiotic marine bacteria in the genus Endozoicomonas. Appl. Microbiol. Biotech.

$622 \quad 100: 8315-8324$.

623 Neave M, Rachmawati R, Xun L, Michell CT, Bourne DG, Apprill A, Voolstra CR

624 (2017) Differential specificity between closely related corals and

625 abundant Endozoicomonas endosymbionts across global scales. ISME J 11:186-200.

626 Palumbi SR, Barshis DJ, Traylor-Knowles N, Bay RA (2014) Mechanisms of reef coral

627 resistance to future climate change. Science 344:895-898.

628 Pantos O, Bongaerts P, Dennis PG, Tyson GW, Hoegh-Guldberg O (2015) Habitat-specific

629 environmental conditions primarily control the microbiomes of the coral Seriatopora 630 hystrix. ISME J. 9:1916-1927.

631 Papina M, Meziane T, van Woesik R (2003) Symbiotic zooxanthellae provide the host-coral

632 Montipora digitata with polyunsaturated fatty acids. Comp Biochem Physiol B Biochem Mol

633 Biol. 35:533-537.

634 Pier J-J (2011) Power uprate effect on thermal effluent of nuclear power plants in Taiwan. In:

635 Tsvetkov P, ed. Nuclear power-operation, safety and environment. Rijeka: InTech

636 Publication, 287.

637 Pogoreutz C, Rädecker N, Cárdenas A, Gärdes A, Wild C, Voolstra, CR (2018) Dominance of

638 Endozoicomonas bacteria throughout coral bleaching and mortality suggests structural

639 inflexibility of the Pocillopora verrucosa microbiome. Ecol Evol 8:2240-2252.

640 Roder C, Bayer T, Aranda M, Kruse M, Voolstra CR (2015) Microbiome structure of the fungid

641 coral Ctenactis echinata aligns with environmental differences. Mol. Ecol. 24:3501-3511.

642 Rosado PM, Leite1 DCA, Duarte GAS, Chaloub RM, Jospin G, da Rocha UN, Saraiva JP, Dini-

643 Andreote F, Eisen JA, Bourne DG, Peixoto RS (2019) Marine probiotics: increasing coral

644 resistance to bleaching through microbiome manipulation. ISME J 13:921-936.

645 Röthig T, Ochsenkühn MA, Roik A, Merwe R, Voolstra CR (2016) Long-term salinity tolerance

646 is accompanied by major restructuring of the coral bacterial microbiome. Mol. Ecol. 25:1308$647 \quad 1323$.

648 Sharp KH, Pratte ZA, Kerwin AH (2017) Season, but not symbiont state, drives microbiome 649 structure in the temperate coral Astrangia poculata. Microbiome 5, 120.

650 Sinensky M (1974) Homeoviscous adaptation-a homeostatic process that regulates the viscosity 651 of membrane lipids in Escherichia coli. Proc Natl Acad Sci USA. 71:522-525.

652 Sheu S-Y, Lin K-R, Hsu M-Y, Sheu D-S, Tang S-L, Chen W-M (2017) Endozoicomonas

653 acroporae sp. nov., isolated from Acropora coral. Int J Syst Evol Microbiol 67:3791-3797. 
654 Shiu J-H, Keshavmurthy S, Chiang P-W, Chen H-J, Lou S-P, Tseng C-H, Hsieh HJ, Chen CA, 655 Tang S-L (2017) Dynamics of coral-associated bacterial communities acclimated to 656 temperature stress based on recent thermal history. Sci Rep 7:14933.

657 Shiu JH, Ding JY, Tseng CH, Lou SP, Mezaki T, Wu YT, Wang HI, Tang SL (2018) A newly

658 designed primer revealed high phylogenetic diversity of Endozoicomonas in coral reefs.

659 Microbes Environ. 4:172-185.

660 Shiu J-H, Yu S-P, Fong C-L, Ding J-Y, Tan C-J, Fan T-Y, Lu C-Y and Tang S-L (2020) Shifting

661 in the dominant bacterial group Endozoicomonas is independent of the dissociation with coral 662 symbiont algae. Front. Microbiol. 11:1791.

663 Silverstein RN, Correa AMS, Baker AC (2012) Specificity is rarely absolute in coral-algal 664 symbiosis: implications for coral response to climate change. Proc R Soc Lond B 279:26096652618.

666 Stat M, Gates RD (2011) Clade D Symbiodinium in scleractinian corals: a "nugget" of hope, a 667 selfish opportunist, an ominous sign, or all of the above? J Mar Biol Article ID 730715.

668 Tchernov D, Gorbunov MY, de Vagas C, Yadav SN, Milligan AJ, Haeggblom M, Falkowski PG 669 (2004) Membrane lipids of symbiotic algae are diagnostic of sensitivity to thermal bleaching

671

672 in corals. Proc Natl Acad Sci 101:13531-13535.

van Oppen MJH, Lough JM (2018) Synthesis: Coral Bleaching: Patterns, Processes, Causes and Consequences. In: van Oppen M., Lough J. (eds) Coral Bleaching. Ecological Studies

675

676 (Analysis and Synthesis), vol 233. Springer, Cham.

Wang J-T, Chen Y-Y, Tew KS, Meng P-J, Chen CA (2012) Physiological and biochemical performances of menthol-induced aposymbiotic corals. PLoS ONE 7(9):e46406.

677

Wang J-T, Wang Y-T, Keshavmurthy S, Meng P-J, Chen CA (2019) The coral Platygyra

678 verweyi exhibits local adaptation to long-term thermal stress through host-specific

679 physiological and enzymatic response. Sci. Rep. 9:13492.

680

Weis VM (2008) Cellular mechanisms of cnidarian bleaching: stress causes the collapse of

681 symbiosis. J Exp Biol 211:3059-3066.

682

Yang CS, Chen MH, Arun AB, Chen CA, Wang JT, Chen WM (2010). Endozoicomonas

683 montiporae sp. nov., isolated from the encrusting pore coral Montipora aequituberculata. Int

684 J Syst Evol Microbiol. 60:1158-1162.

685

Ziegler M, Seneca FO, Yum LK, Palumbi SR, Voolstra CR (2017) Bacterial community 686 
687 Figure legends

688 Fig. 1. Response of corals Platygyra verweyi, Isopora palifera, and Stylophora pistillata to acute

689

690

691

692

693

694

695

696

697

698

699

700

701

702

703

704

705

706

707

708

709

710

711

712

713

714

715

716

717

718

719

720

721 heat stress at $31^{\circ} \mathrm{C}$. Data points represent changes in maximum quantum yield of PSII (A) and algal density (B) over time.

Fig. 2. Comparison of fatty acid composition between menthol-bleached Platygyra verweyi and Isopora palifera. Principal component analysis of fatty acid composition (A) and degree of saturation of each dominant fatty acid (B) are presented. Stars above means are significantly different at $\mathrm{P}=0.05$ (t-test).

Fig. 3. Changes in the antioxidant activity of Platygyra verweyi and Isopora palifera host tissues when treated at $31^{\circ} \mathrm{C}$. The data points in (A) are the activity of superoxide dismutase (SOD) and in (B) are catalase (CAT). Means followed by the same letter are not significantly different at $\mathrm{P}=0.05$ (Tukey's post hoc analysis).

Fig. 4. Multi-dimensional scaling (MDS) ordination of arc cosine-transformed relative abundance $(\%)$ in $\gamma$-proteobacteria composition associating with Platygyra verweyi and Isopora palifera $($ stress $=0.01)$. Empty symbols represent data from $P$. verweyi at $31{ }^{\circ} \mathrm{C}$ for $0 \mathrm{~h}(\mathrm{P} 0 \mathrm{H} 1-3)$ and $24 \mathrm{~h}(\mathrm{P} 24 \mathrm{H} 1-3)$; and filled symbols represent that from I. palifera at $31{ }^{\circ} \mathrm{C}$ for $0 \mathrm{~h}$ (I0H1-3) and $24 \mathrm{~h}$ (I24H1-3).

Fig. 5. Dominant bacterial genus composition in the $\gamma$-proteobacteria class in the corals. The data in (A) are derived from Isopora palifera and (B) from Platygyra verweyi, and the numbers $(1,2,3)$ represent three colony replicates. Genera with $<1 \%$ abundances were grouped into others.

Fig. S1. Temperature and light intensity profiles of thermal treatments used in this study. Light was turned off during the illumination regime, as indicated by the red arrow, to conduct dark adaption before PAM quantum yield measurements.

Fig. S2. Fatty acid compositions of menthol-bleached Platygyra verweyi and Isopora palifera.

Fig. S3. Phylum level composition of bacterium consortia of Platygyra verweyi and Isopora palifera. Numbers $(1,2,3)$ represent three colony replicates. (A) contains the samples from Isopora palifera and (B) from Platygyra verweyi. In the legend, the most dominant phylum is marked in a box.

Fig. S4. Class level composition of bacterium consortia in Platygyra verweyi and Isopora palifera. Numbers $(1,2,3)$ represent three colony replicates incubated at $31^{\circ} \mathrm{C}$ for 0 and 24 h. (A) contains samples from Isopora palifera and (B) from Platygyra verweyi. In the legend, the two most dominant classes are marked in a box.

Fig. S5. Detection of Endozoicomonas in Platygyra verweyi and Isopora palifera tissues with semi-quantitative PCR. Samples from 3 replicate colonies (1, 2, and 3) were collected 
before treating with antibiotics or Endozoicomonas infection (Pre-Exp) and 0, 24, 48, and

723 $72 \mathrm{~h}$ heating at $31^{\circ} \mathrm{C}$ for analyses. "Endo" represents the detection of Endozoicomonas.

724

725 


\section{Table $\mathbf{1}$ (on next page)}

Changes in the algal density of Platygyra verweyi and Isopora palifera with and without manipulating the Endozoicomonas association.

The endogenous Endozoicomonas spp. in P. verweyi were inhibited with antibiotics ( $+A b)$ for 9 days and then recovered in clean seawater (recovery from $+A b$ ) for 1 week. I. palifera were inoculated with E. montiporae (+Endo.) or a seawater blank (-Endo.) for $2 \mathrm{~h}$ per day and repeated for 7 days. Algal density $\left(\times 10^{6}\right.$ cells $\left.\mathrm{cm}^{-2}\right)$ in the colonies of $P$. verweyi before antibiotics treatment and I. palifera before Endozoicomonas infection were $(2.6 \pm 0.8) \times 10^{6}$ $\mathrm{cm}^{-2}$ and $(2.3 \pm 1.2) \times 10^{6} \mathrm{~cm}^{-2}$, respectively. Data are expressed as relative percentage of algal density in each treatment to that in the pre-treated colony. 
4 Table 1. Changes in the algal density of Platygyra verweyi and Isopora palifera with and 5 without manipulating the Endozoicomonas association. The endogenous Endozoicomonas 6 spp. in $P$. verweyi were inhibited with antibiotics $(+\mathrm{Ab})$ for 9 days and then recovered in 7 clean seawater (recovery from $+\mathrm{Ab}$ ) for 1 week. I. palifera were inoculated with $E$.

8 montiporae (+Endo.) or a seawater blank (-Endo.) for $2 \mathrm{~h}$ per day and repeated for 7 days.

9 Algal density $\left(\times 10^{6}\right.$ cells $\left.\mathrm{cm}^{-2}\right)$ in the colonies of $P$. verweyi before antibiotics treatment and 10 I. palifera before Endozoicomonas infection were $(2.6 \pm 0.8) \times 10^{6} \mathrm{~cm}^{-2}$ and $(2.3 \pm 1.2) \times 10^{6}$ $11 \mathrm{~cm}^{-2}$, respectively. Data are expressed as relative percentage of algal density in each 12 treatment to that in the pre-treated colony.

\begin{tabular}{|c|c|c|c|c|}
\hline \multirow{2}{*}{ Hours at $31^{\circ} \mathrm{C}$} & \multicolumn{2}{|r|}{ P. verweyi } & \multicolumn{2}{|c|}{ I. palifera } \\
\hline & $+\mathrm{Ab}$ & recovery from $+\mathrm{Ab}$ & +Endo. & -Endo. \\
\hline & \multicolumn{4}{|c|}{$(\%)$} \\
\hline 0 & $140 \pm 47$ & $130 \pm 53$ & $87 \pm 26$ & $90 \pm 42$ \\
\hline 24 & $118 \pm 18$ & $140 \pm 26$ & $26 \pm 15$ & $33 \pm 14$ \\
\hline 48 & $188 \pm 11$ & $111 \pm 57$ & $19 \pm 17$ & $30 \pm 16$ \\
\hline 72 & $153 \pm 72$ & $128 \pm 30$ & $4 \pm 4$ & $21 \pm 21$ \\
\hline $72 \mathrm{~h}$ at $25^{\circ} \mathrm{C}$ & $115 \pm 14$ & $123 \pm 22$ & $80 \pm 26$ & $69 \pm 11$ \\
\hline
\end{tabular}

13

14 
Figure 1

Response of corals Platygyra verweyi, Isopora palifera, and Stylophora pistillata to acute heat stress at $31{ }^{\circ} \mathrm{C}$.

Data points represent changes in maximum quantum yield of PSII (A) and algal density (B) over time. 


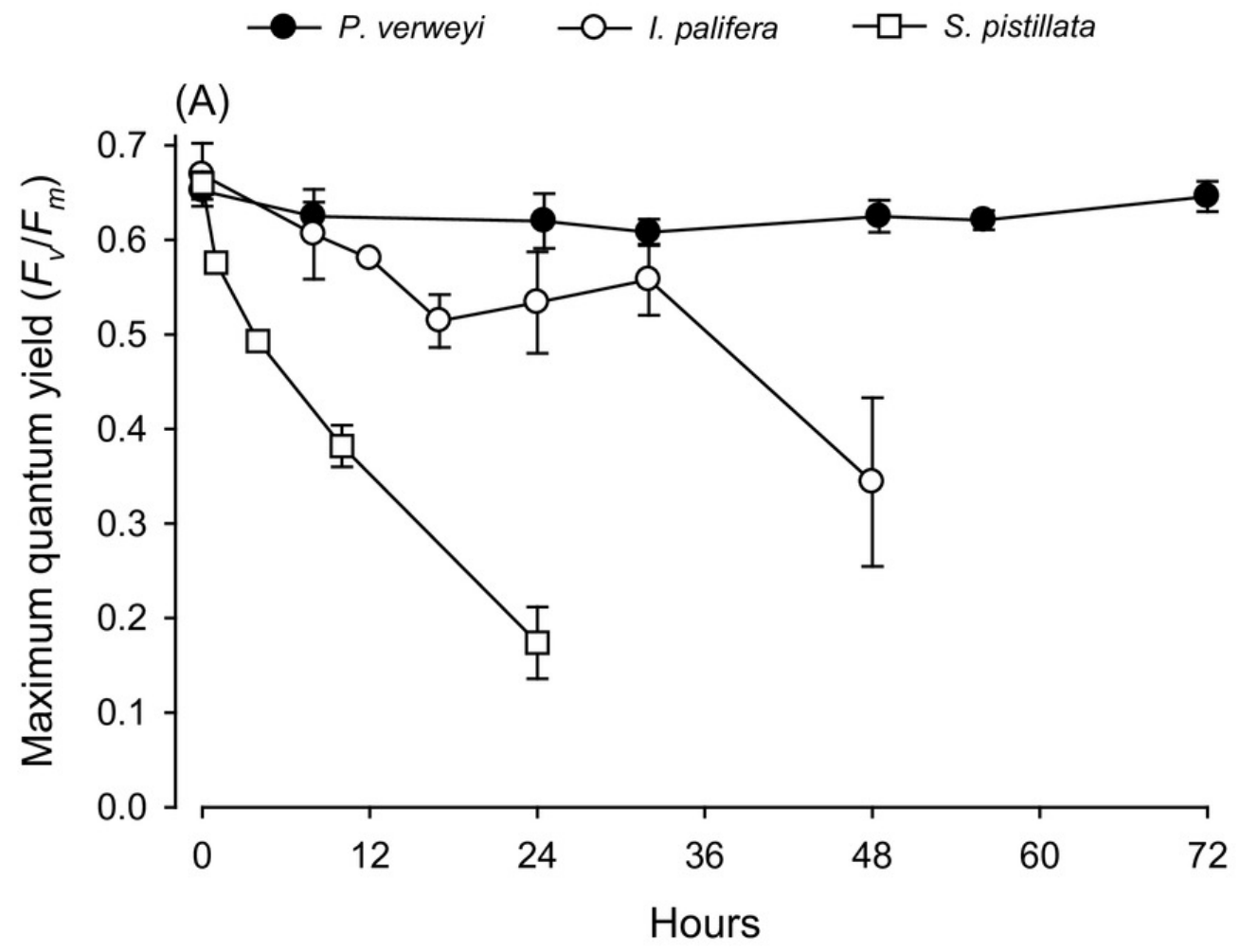

(B)

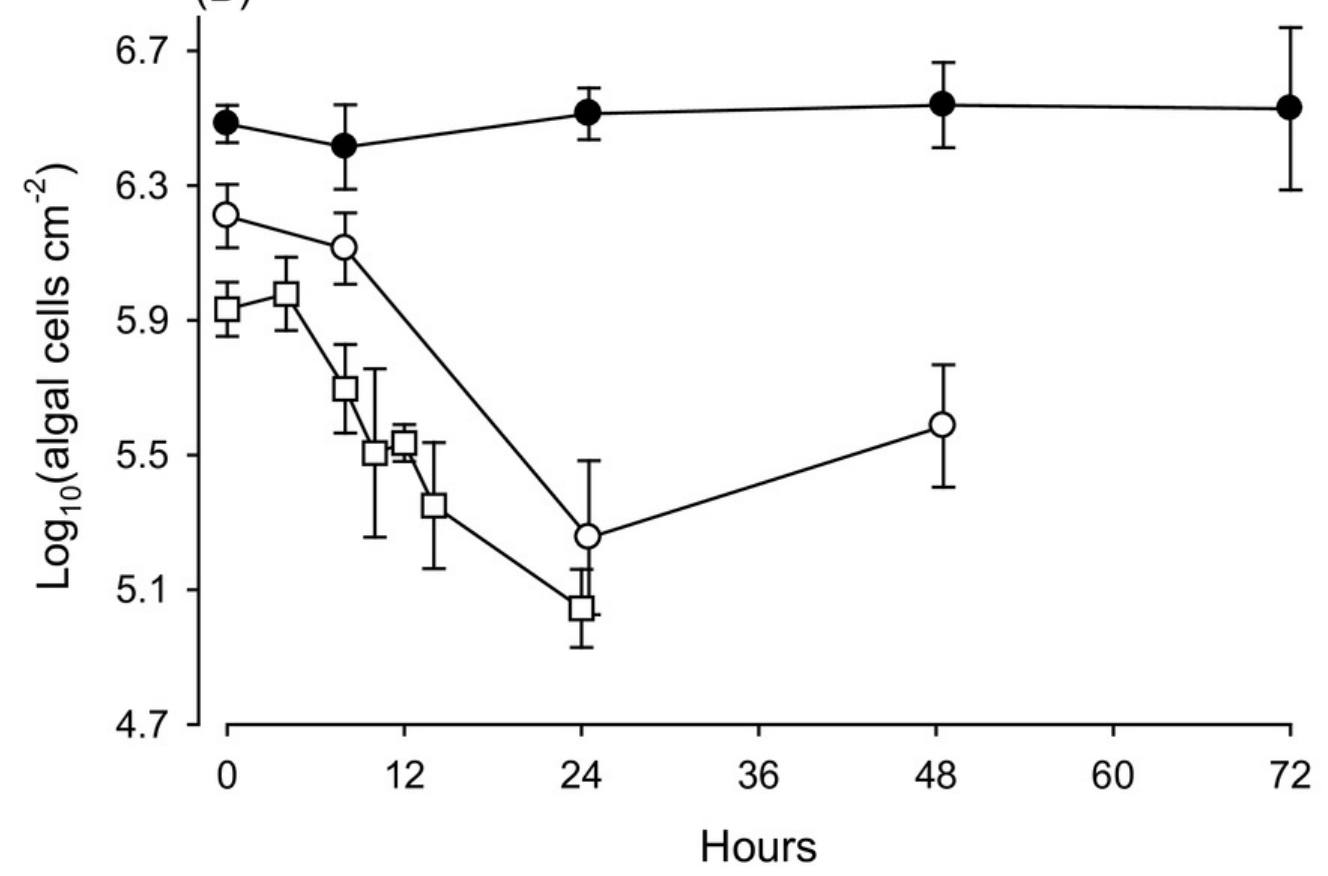


Figure 2

Comparison of fatty acid composition between menthol-bleached Platygyra verweyi and Isopora palifera.

Principal component analysis of fatty acid composition $(A)$ and degree of saturation of each dominant fatty acid $(B)$ are presented. Stars above means are significantly different at $P=$ 0.05 (t-test). 

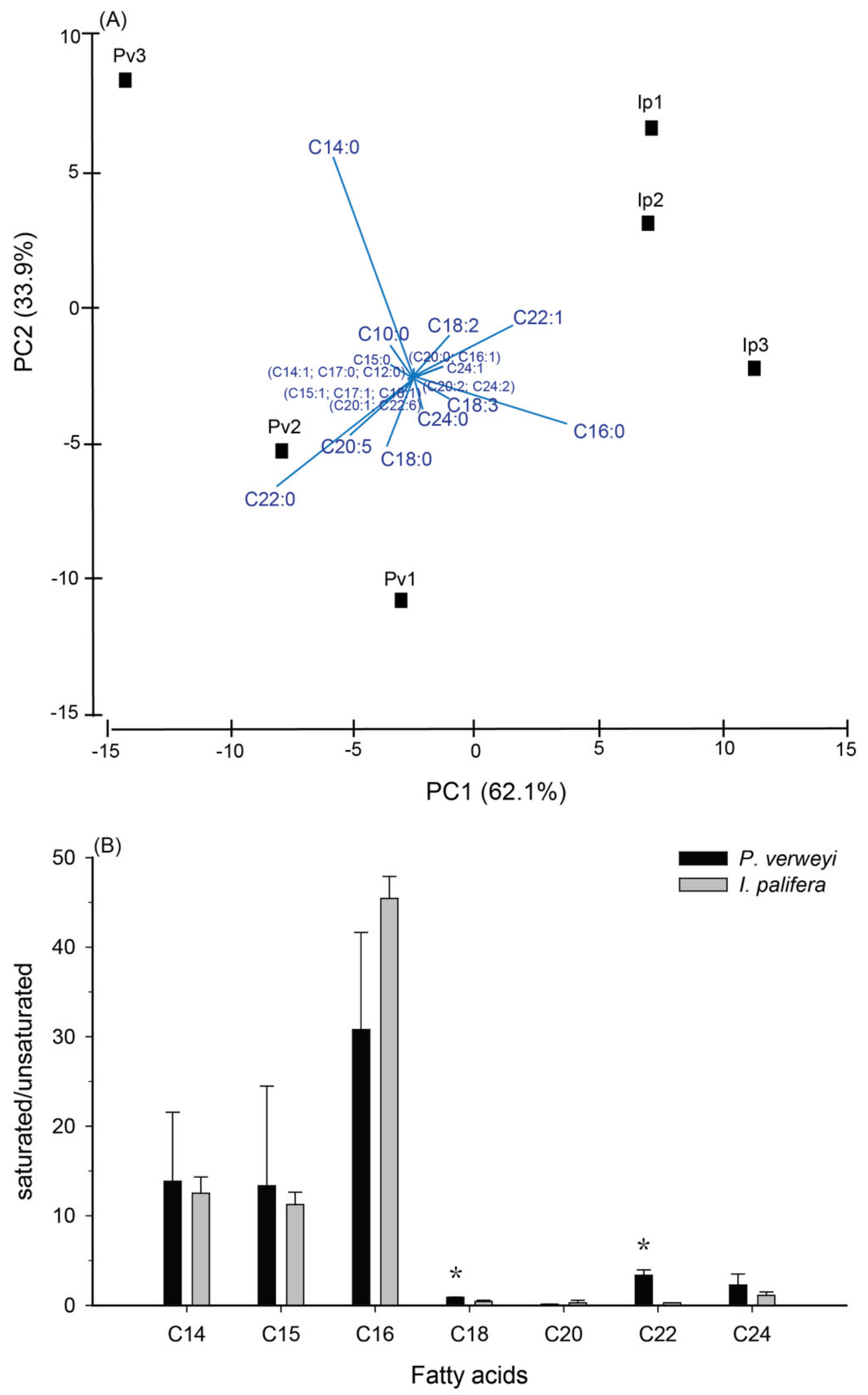

Peer] reviewing PDF | (2021:06:61888:4:0:NEW 9 Dec 2021) 
Figure 3

Changes in the antioxidant activity of Platygyra verweyi and Isopora palifera host tissues when treated at $31{ }^{\circ} \mathrm{C}$.

The data points in (A) are the activity of superoxide dismutase (SOD) and in (B) are catalase (CAT). Means followed by the same letter are not significantly different at $P=0.05$ (Tukey's post hoc analysis). 


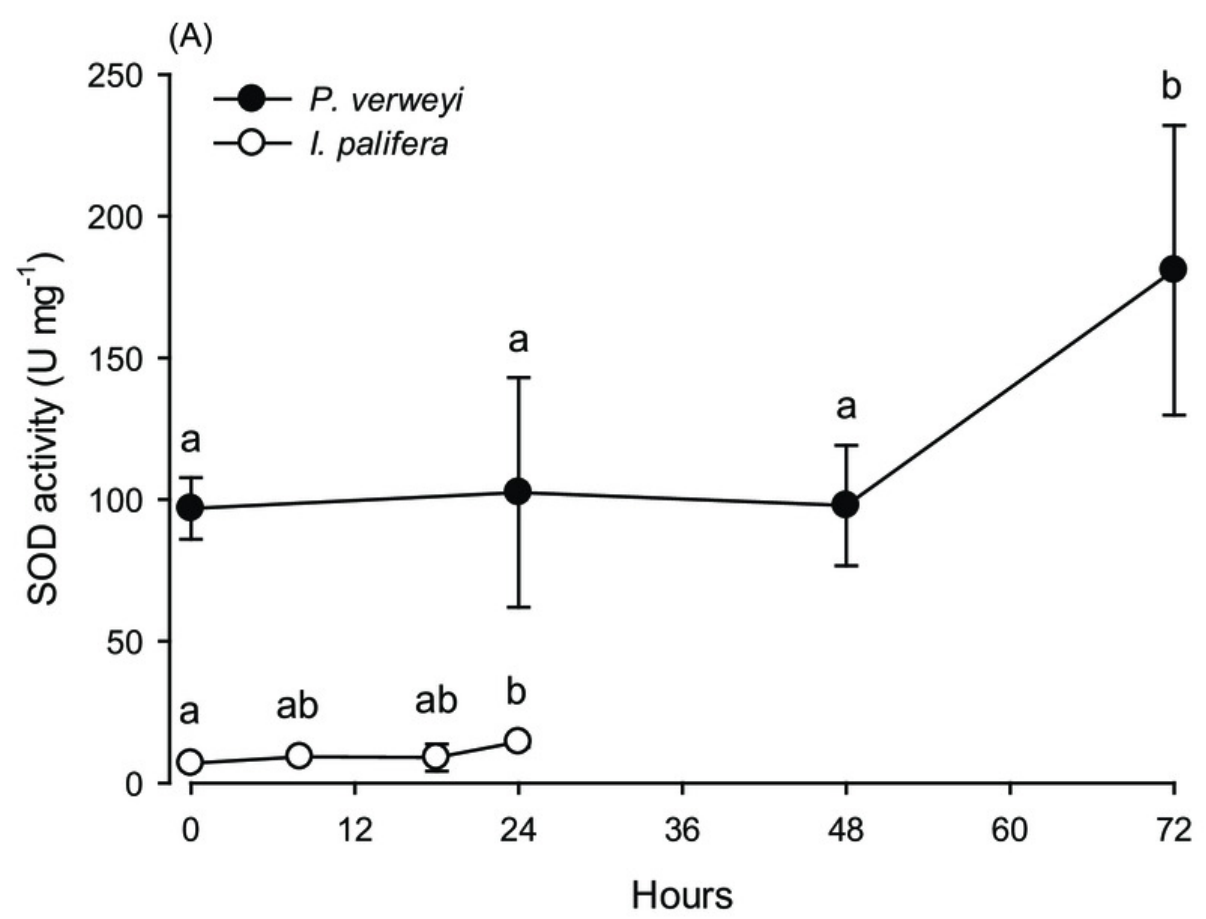

(B)

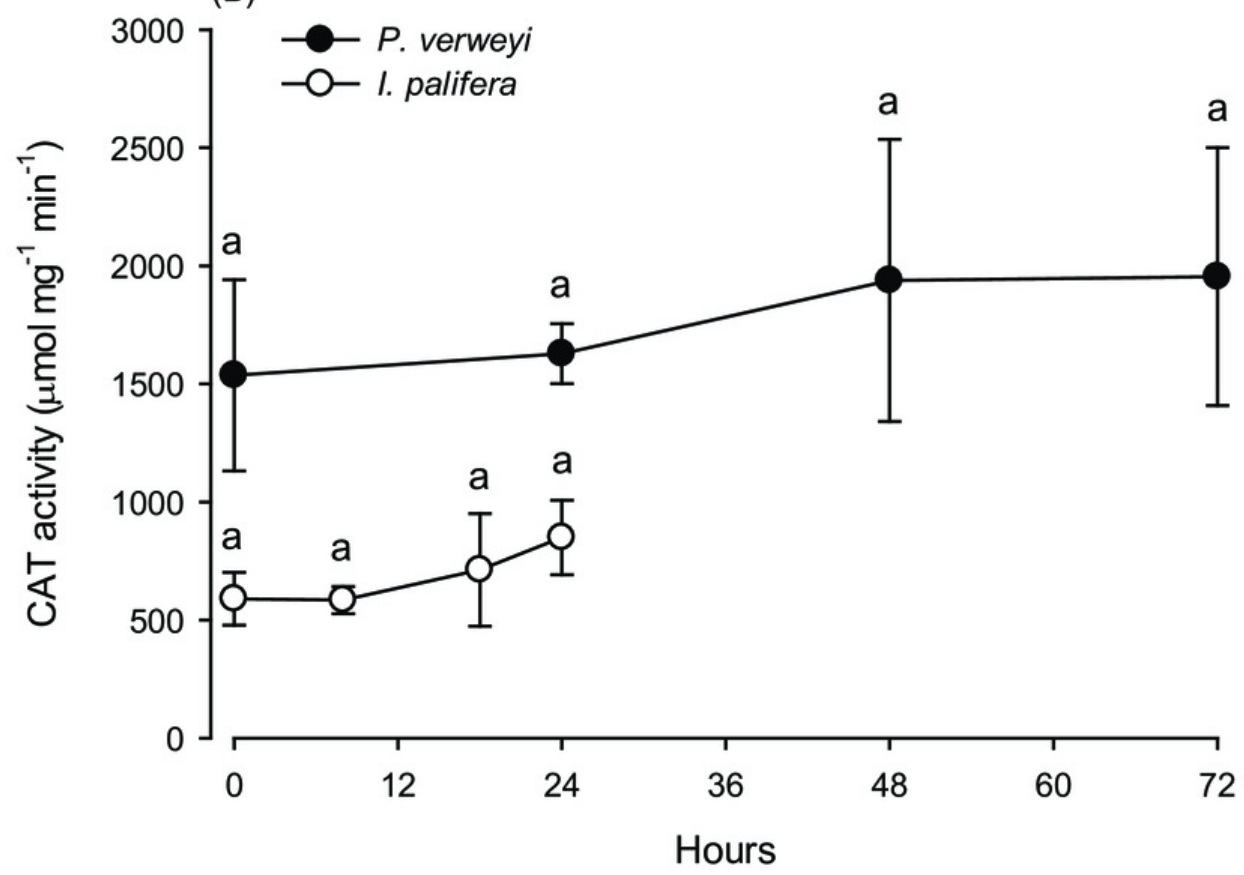


Figure 4

Multi-dimensional scaling (MDS) ordination of arc cosine-transformed relative abundance (\%) in $\gamma$-proteobacteria composition associating with Platygyra verweyi and Isopora palifera (stress $=0.01$ ).

Empty symbols represent data from $P$. verweyi at $31{ }^{\circ} \mathrm{C}$ for $0 \mathrm{~h}(\mathrm{POH} 1-3)$ and $24 \mathrm{~h}(\mathrm{P} 24 \mathrm{H} 1-3)$; and filled symbols represent that from I. palifera at $31{ }^{\circ} \mathrm{C}$ for $0 \mathrm{~h}(\mathrm{IOH} 1-3)$ and $24 \mathrm{~h}(\mathrm{I} 24 \mathrm{H} 1-3)$.

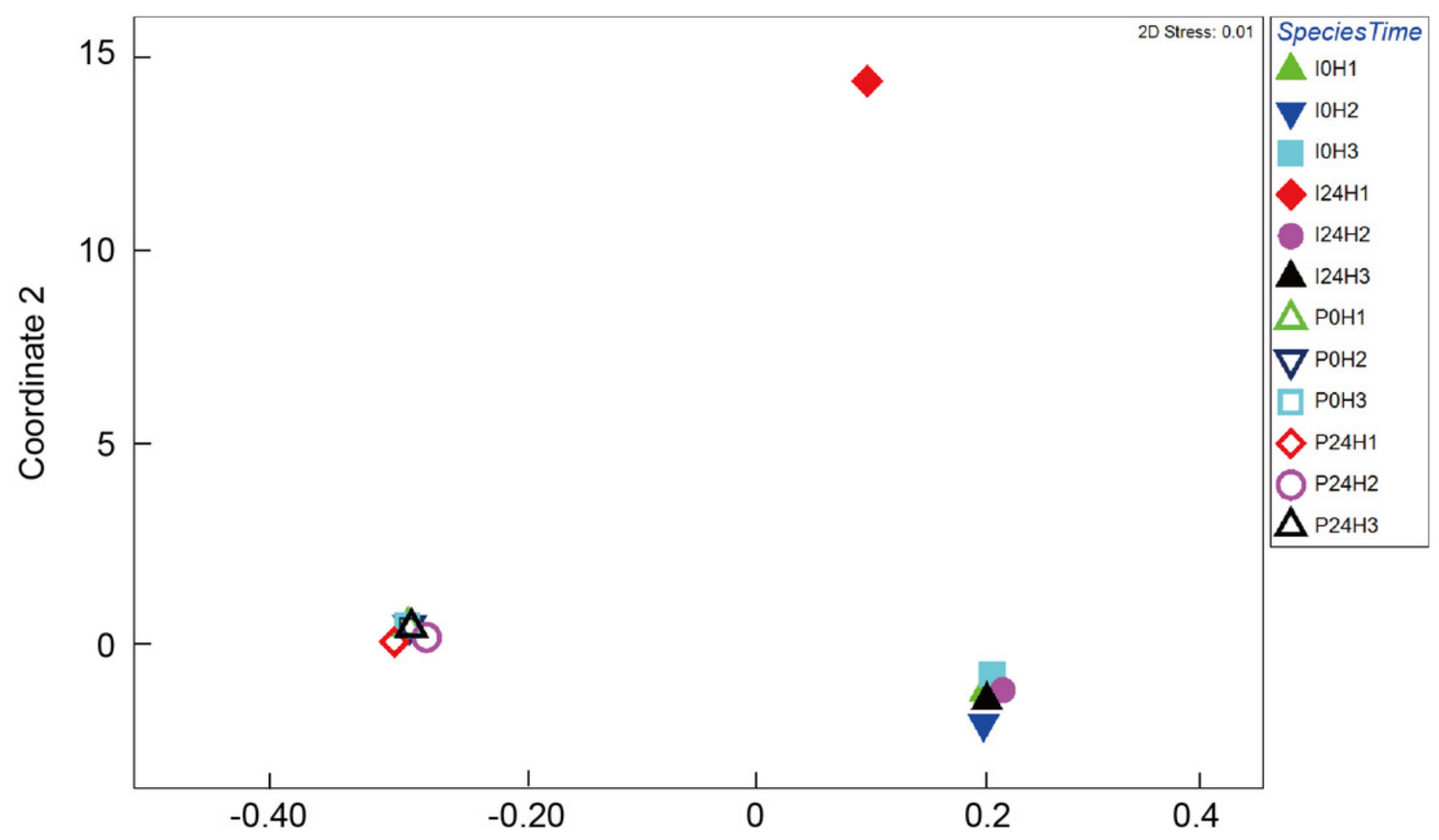

Coordinate 1 


\section{Figure 5}

Dominant bacterial genus composition in the $\mathrm{\gamma}$-proteobacteria class in the corals.

The data in (A) are derived from Isopora palifera and (B) from Platygyra verweyi, and the numbers $(1,2,3)$ represent three colony replicates. Genera with $<1 \%$ abundances were grouped into others.

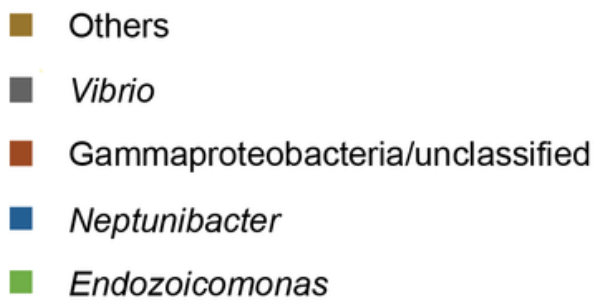

(A)

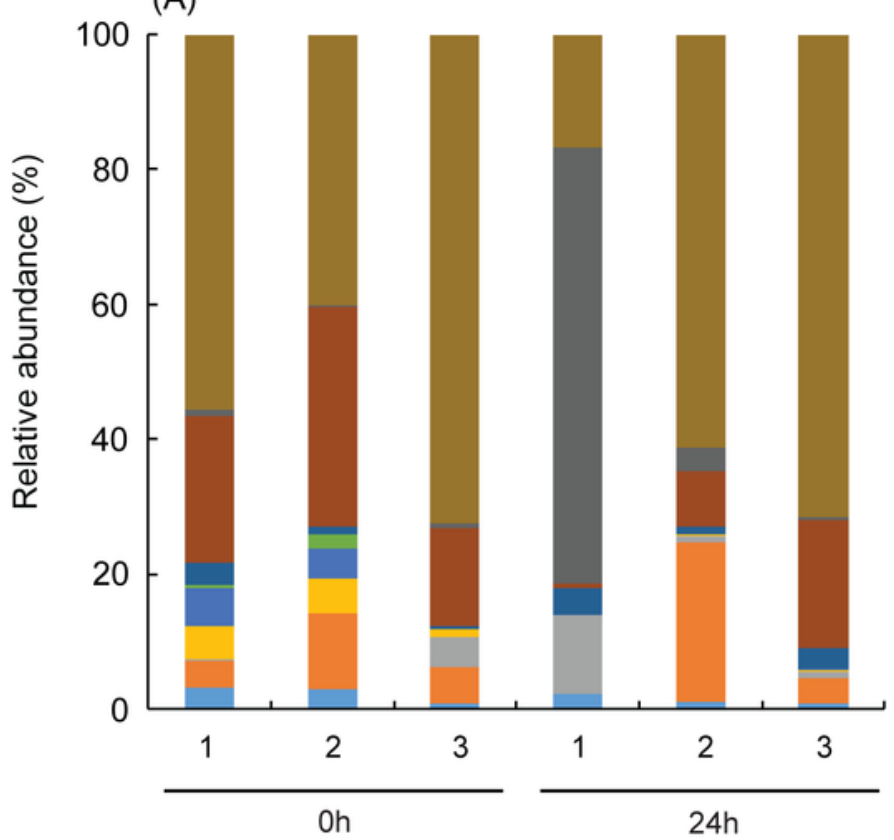

Eionea

- HTCC5015

- Ferrimonas

- Thalassotalea

- Alteromonadaceae/unclassified

(B)

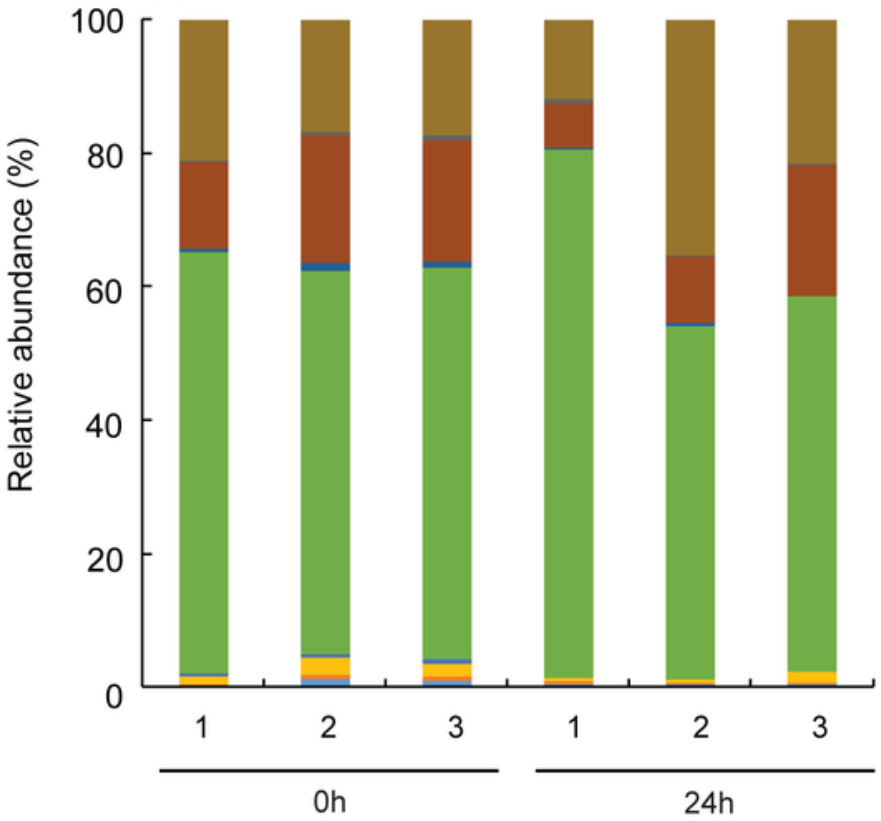

